\title{
Implementing an evidence-based intervention to improve care for ventilator-dependent residents in a nursing home facility
}

\author{
Angela Espinoza Adams *, Carole Leone White, Gemma Trieste Kennedy \\ School of Nursing, University of Texas Health Science Center at San Antonio, United States
}

Received: November 4, 2014

Accepted: February 5, $2015 \quad$ Online Published: March 2, 2015

DOI: $10.5430 /$ cns.v3n2p109

URL: http://dx.doi.org/10.5430/cns.v3n2p109

\begin{abstract}
Introduction: Pneumonia is a potentially preventable cause of readmissions among nursing home residents. It was found to be a frequent cause of readmission among ventilator-dependent residents in a nursing home facility. The objective of this project was to implement and evaluate a comprehensive respiratory care program for residents dependent on ventilators and potentially decrease the readmission rate in a community nursing home.

Methods: A quality improvement project was undertaken to improve the care provided to ventilator-dependent resident. Components of the project included implementation of the ventilator associated pneumonia (VAP) protocol, a hand hygiene bundle, and an education program on respiratory care. To assess the program impact, process monitoring of the elements of the VAP protocol, adherence to hand hygiene, and readmission rates were undertaken at baseline and following implementation of the program.

Results: The VAP protocol was successfully implemented through education, changes to documentation, and an institutional policy. Process auditing showed improvement over time in adherence to the two elements of the protocol, elevation of head of bed and daily oral care, directly related to VAP prevention. Correct hand washing occurred $12 \%$ of the time, increasing to $68 \%$ at 6 weeks post-implementation; however, adherence decreased to $35 \%$ at the 7 months follow-up. A chart review of the reasons for readmission showed a downward trend in readmissions related to pneumonia from $29 \%$ pre-intervention to $9 \%$ following the intervention.

Conclusions: This project reflects an improvement in the care provided to residents dependent on ventilators. This was accomplished by adapting the VAP protocol to fit within the nursing home context.
\end{abstract}

Key Words: Evidence-based intervention, Ventilator associated pneumonia, Respiratory care, Nursing

\section{Introduction}

Approximately 1.4 million Americans reside in the nation's 15,800 nursing homes at any time. ${ }^{[1]}$ This fragile and vulnerable group must be able to count on the nursing homes where they reside to provide reliable and high quality care. The Centers for Medicare \& Medicaid Services (CMS) contract with state survey agencies to conduct surveys to eval- uate the quality of care provided to residents, as well as investigate complaints to determine if the nursing homes who participate in the Medicare and Medicaid programs are complying with federal quality standards. Research has revealed deficiencies in the quality of care delivered in nursing homes. ${ }^{[2]}$

Interventions to improve the quality of care have been a ma-

\footnotetext{
* Correspondence: Angela Espinoza Adams; Email: angelanpadams@ yahoo.com; Address: School of Nursing, University of Texas Health Science Center at San Antonio, United States.
} 
jor focus of federal quality initiatives, starting with the passage of the Omnibus Reconciliation Act of 1987 (OBRA). This act set new provisions for Medicare and Medicaid sections relating to new standards for care in the nursing home setting.

There are many challenges to implementing and measuring quality of care in nursing home facilities, including difficulties for staff in understanding and interpreting the CMS quality measures and also in how to apply them for quality improvement (QI). ${ }^{[3]} \mathrm{Li}$ and colleagues ${ }^{[4]}$ developed a program to provide onsite consultation and training to nursing home staff to improve compliance with federal and state regulations related to quality and also to improve nursing home clinical practice. In a national survey to examine the effectiveness of their program, they reported barriers to QI, including a lack of appropriate staff and funding to initiate and sustain the quality programs. In applying an evidence-based approach to QI, a focus on organizational context including culture, leadership and evaluation is essential for implementation and sustainability. ${ }^{[5]}$

Readmissions from nursing home facilities to acute care hospitals are a critical health care issue, impacting both quality and safety for nursing home residents. Mor, et al. ${ }^{[6]}$ reported that in 2006 almost $25 \%$ of nursing home residents were readmitted to an acute care facility within 30 days of nursing home admission, at a cost of $\$ 4.34$ billion. A more recent study conducted in 2011 by the Department of Health and Human Services reported similar readmission rates among Medicare nursing home residents, but found that the costs had tripled to $\$ 14.3$ billion. $^{[7]}$ In addition to increasing healthcare costs, readmissions are traumatic for residents and their families, and place residents at risk for iatrogenic complications that can cause loss of functional abilities and morbidity, compounding healthcare expenditures. ${ }^{[8]}$ A project funded by CMS examined readmissions from nursing homes using 2005 Medicare and Medicaid claims. Findings from the study suggested that about $63 \%$ of readmissions from a Medicaid-covered nursing facility and $19 \%$ from a Medicare-covered skilled nursing facility were potentially avoidable hospitalizations. ${ }^{[9]}$ Five conditions, namely pneumonia, congestive heart failure, urinary tract infections, dehydration, and chronic obstructive pulmonary disease and asthma were found to be responsible for $78 \%$ of the potentially avoidable hospitalizations. ${ }^{[9]}$

Despite the significant role of pneumonia in contributing to preventable readmissions from nursing homes, few studies have examined strategies to improve the quality of respiratory care provided to nursing home residents. Readmissions related to respiratory distress may be particularly important for nursing homes that provide care to residents who are dependent on ventilators. Evidence is accumulating about the effectiveness of the ventilator-associated pneumonia (VAP) protocol to reduce adverse outcomes for ventilated patients. ${ }^{[10,11]}$ The VAP protocol focuses on elements of care designed to decrease pneumonia in patients who are ventilated and includes oral hygiene, head elevation, drug sedation holiday, and prophylaxis for deep vein thrombosis and gastric ulcers. Most published studies, however, have focused on the implementation and outcomes related to the VAP protocol within the intensive care unit. ${ }^{[11-14]}$ One study examined the use of the VAP protocol with ventilated longterm care spinal-cord injured patients residing in a nursing home. ${ }^{[15]}$ Within this small sample of 19 spinal cord injury patients, the authors reported a decrease in the ventilator associated pneumonia rate from 7.5 to 0 per 1,000 ventilator days after the implementation of the VAP protocol.

Nursing home residents who are ventilator-dependent may not be receiving evidence-based respiratory care which places them at high risk for respiratory complications and subsequent readmission to an acute care facility. It has been suggested that other factors, in addition to the VAP bundle elements, such as a concurrent improvement program that is focused on the patient on the ventilator, may be important in the reduction of ventilator-associated pneumonia. ${ }^{[10]}$ The purpose of this project was to implement a comprehensive intervention that, in addition to the VAP protocol, also included education with nursing staff regarding ventilator care and respiratory distress, and a hand hygiene bundle.

\section{Methods}

\subsection{Setting}

The quality program was conducted at a 120-bed for-profit community nursing home, with about $40 \%-50 \%$ of residents receiving ventilator support. The majority of care is provided by licensed vocational nurses, who must practice under the supervision of a registered nurse or a physician. Related to the high number of ventilator-supported residents, the respiratory therapy department is an integral component of the nursing home and they provide 24-hour coverage. Residents receive ventilator-care for a variety of diagnoses including severe chronic obstructive pulmonary disease, chronic and acute respiratory failure, amyotrophic lateral sclerosis, myasthenia gravis, and multiple sclerosis. This project was accomplished through two phases which included an assessment of readmissions and the organizational culture and context, which subsequently guided the design and implementation of the intervention (see Figure 1). The project was submitted to the Institutional Review Board and it was considered quality improvement and deemed exempt from review.

\subsection{Procedures}

The assessment of readmissions demonstrated a monthly readmission rate between 7 and 11 readmissions per 1,000 resident days (see Figure 2). To identify the contributions of respiratory distress and pneumonia to readmissions, information was abstracted from the charts of residents who were 
readmitted in December 2011 and April 2012, using the INTERACT quality improvement tool. ${ }^{[16]}$ The tool has been used in a quality improvement program, designed to improve the early identification, assessment, documentation, and communication regarding changes in the resident's status in skilled nursing facilities. ${ }^{[1]}$ The results of the chart reviews demonstrated that approximately one-third of readmissions were related to a "new condition", specifically respiratory distress and pneumonia (29\%), and of these, over half $(59 \%)$ occurred in residents who were ventilatordependent. These data clearly indicated an opportunity for improvement at this local nursing home.

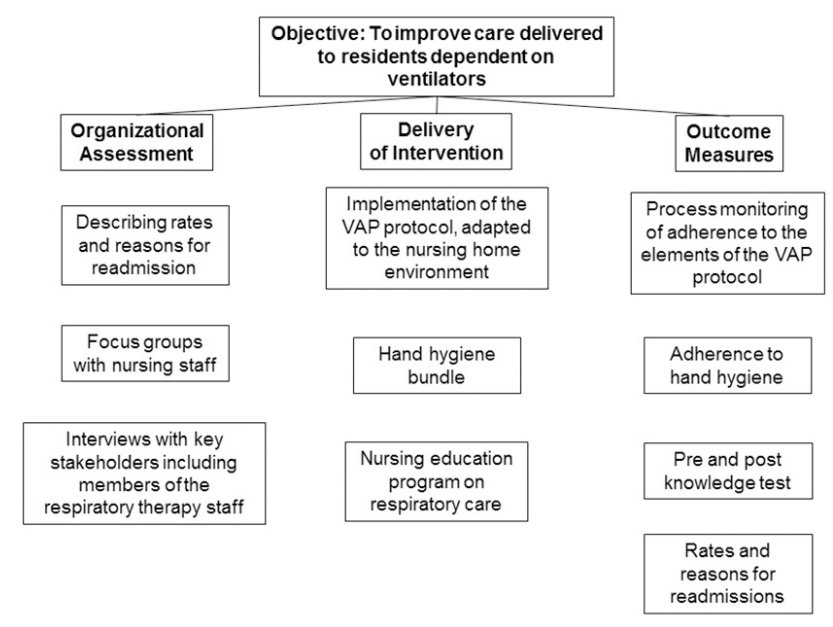

Figure 1: Flow chart showing components of quality improvement project

Focus groups were conducted with nursing staff using a semi-structured interview guide developed by the project team. Nurses described their limited knowledge and lack of confidence in caring for residents who were ventilatordependent and also residents with respiratory distress. The need for ongoing education in this area was a consistent theme across the focus groups. Individual interviews were conducted with respiratory therapists and revealed similar concerns about nursing knowledge and also concerns about infection control procedures. The respiratory therapists described the lack of a systematic approach to the care of residents who were ventilator-dependent and suggested that the VAP protocol could address this gap.

The implementation of the comprehensive respiratory care program was accomplished through a collaborative approach with administration, nursing, medicine, and respiratory therapy. The project was a multi-faceted approach with the following components: the VAP protocol, hand-washing awareness event, and a nursing education program.

The VAP protocol includes the following five elements: elevation of the head of the bed between 30 and 45 degrees, daily oral care with chlorhexidine, peptic ulcer disease pro- phylaxis treated with proton pump inhibitors (PPI), deep venous thrombosis (DVT) prophylaxis, and daily sedative interruption. ${ }^{[18]}$ The VAP protocol was tailored to the nursing home setting, with implementation and process monitoring of four of the five VAP elements. The fifth element, a sedation holiday for weaning preparation, was not included, partly due to the fact that many of the residents are not able to be weaned because of chronic diseases. The respiratory therapy supervisor, in conjunction with the pulmonologist, revised the respiratory flow sheet to include head of bed elevation and oral care components of the VAP protocol. The facility assigned a staff member to perform oral care on all residents who were ventilated and purchased a cart for the oral care items, such as the chlorhexidine and dental kits, to facilitate the provision of oral care. To enhance adherence to the VAP protocol, a policy was written for implementation of the protocol and a standardized admission order-set that included the four elements of the protocol was developed. Education was ongoing related to the VAP protocol and its elements.

The second component focused on hand hygiene. The goal was to create awareness of hand-washing, increase staff knowledge about the correct hand washing technique, and improve adherence with hand washing. Strategies included a nurse champion for hand-washing on all shifts, education about the correct technique for hand-washing, and flyers and posters to raise awareness of hand washing.

The third component of the comprehensive intervention was an educational program for the nursing staff regarding the care of a patient in respiratory distress, including respiratory distress in ventilated patients. This program was augmented by hands-on ventilator education, presented by the respiratory therapy supervisor. Along with the respiratory content, oral care and hand hygiene methods were reviewed.

\subsection{Measurement and analysis}

Outcomes measured in the project included adherence to the elements of the VAP protocol, nursing knowledge as measured through a pre and post-test, percentage of staff performing correct hand hygiene, and readmissions related to respiratory distress. Bar graphs were used to display the data related to VAP adherence, nursing knowledge, and hand-washing. Reasons for readmission were examined using the INTERACT tool and readmission rates over time were examined utilizing a statistical process control chart. All analyses were performed using Microsoft Excel 2011 and QI Macros for Excel.

\section{Results}

This project was accomplished through collaboration of nursing leadership $(n=2)$, respiratory technology $(n=$ $10)$, medical staff $(n=1)$ and a nurse practitioner (project leader). The program was delivered to approximately $80 \%$ 
of the licensed vocational nurses working in the nursing facility.

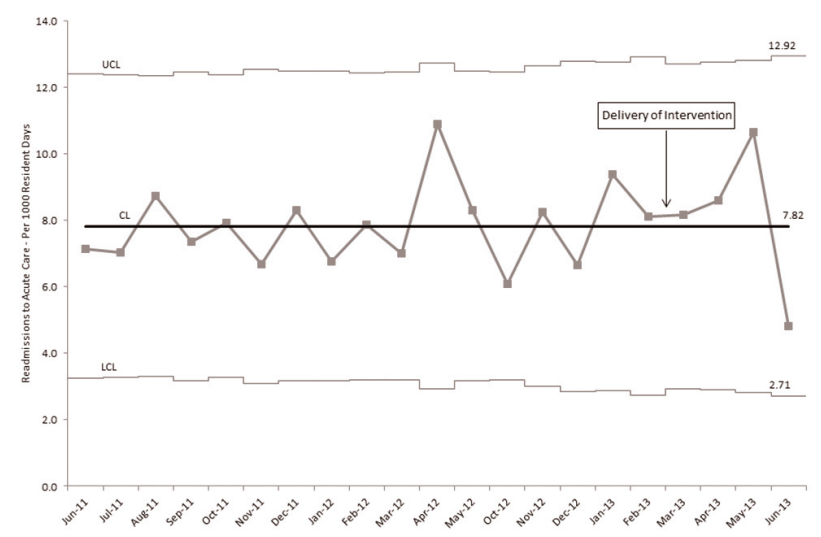

Figure 2: Statistical process control chart indicating admission rate per 1,000 resident days before and after quality improvement intervention

Adherence to the elements of the VAP protocol was examined at baseline (pre-implementation) and at 6 weeks (postintervention 1) and 7 months (post-intervention 2) after implementation through chart audits and bedside observation. All ventilator-dependent residents were included in each audit. The 4 components showed improvement from baseline to 6 weeks although the differences were not statistically significant. As can be seen in Figure 3, adherence to head of bed elevation was already high at baseline but improved to $100 \%$ at both 6 weeks and 7 months post implementation. Oral care also showed improvement from a baseline rate of $33 \%$ to $39 \%$ and $59 \%$ at 6 weeks and 7 months respectively. DVT prophylaxis was $51 \%$ at baseline and increased to $60 \%$ at 6 weeks, with a decrease to $29 \%$ at 7 months post implementation. Finally, the use of PPIs was $89 \%$ at baseline, $95 \%$ at 6 weeks, and $75 \%$ at 7 months.

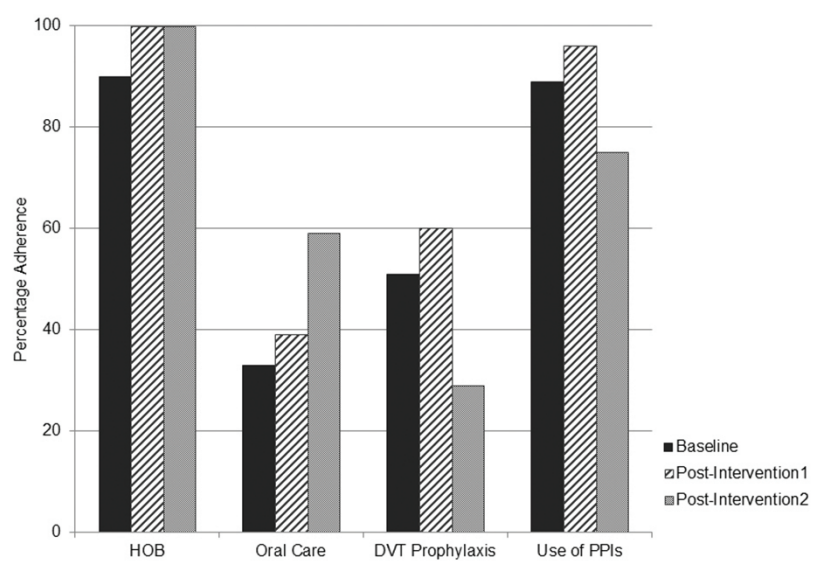

Figure 3: Adherence to the elements of the ventilatorassociated pneumonia protocol before and after quality improvement intervention
Hand hygiene adherence was examined through direct observation of the opportunities for hand-washing and observed occurrences of correct technique. All staff, including nursing, respiratory technicians, rehabilitation therapists, and house-keeping, were observed but adherence was not examined by role. At baseline, hand washing using the correct technique occurred only $12 \%$ of the time and this increased to $68 \%$ at 6 weeks post-implementation (see Figure 4). By the 7 month assessment, adherence with hand hygiene had decreased to $35 \%$.

Nursing knowledge related to caring for a resident in respiratory distress was assessed through a 10-item test, given prior to the education program and at the completion of the program. Overall, there was an improvement in the percentage of correct scores between the pre and post-tests, from a mean of $78 \%$ on the pre-test to $91 \%$ on the post-test. In particular, the items related to the assessment of respiratory distress showed the greatest improvement. For example, the item assessing knowledge around identifying subtle clinical signs of respiratory distress was scored correctly by $45 \%$ on the pre-test and increased to $86 \%$ on the post-test. The ventilator hands-on training was also reported as very beneficial as it gave them a chance to handle the ventilator in a non-threatening environment and also allowed them to ask questions. Feedback from the nurses regarding the education program was very positive, including requests to repeat the respiratory update on a regular basis.

Following the implementation of the comprehensive program, readmission rates over a 6-month period ranged from 4.8 to 10.6 readmissions per 1,000 resident days (see Figure 2 ). In contrast to the baseline chart review where respiratory conditions were found to account for the $29 \%$ of readmissions, a chart review conducted at two months after the program implementation showed that respiratory conditions accounted for only $9 \%$ of the readmissions.

\section{Discussion}

This respiratory quality improvement program was undertaken in response to the high readmission rate in this local nursing facility, with a high percentage of readmission related to respiratory complications. Using a multidisciplinary approach, an educational program was undertaken along with implementation of the VAP protocol. A recent study reported the apprehension that nursing home staff feel in caring for patients on ventilators. ${ }^{[19]}$ In fact, caring for a patient on a ventilator was rated as the top reason to refuse a transfer. Nursing staff in our study also reported their apprehension and concern about caring for residents on ventilators. Their informal feedback following the education program was that it improved their confidence in caring for these residents and they requested ongoing educational programs in this area. The testing conducted before and after the program demonstrated an improvement in 
their knowledge in the care of patients who are ventilatordependent.

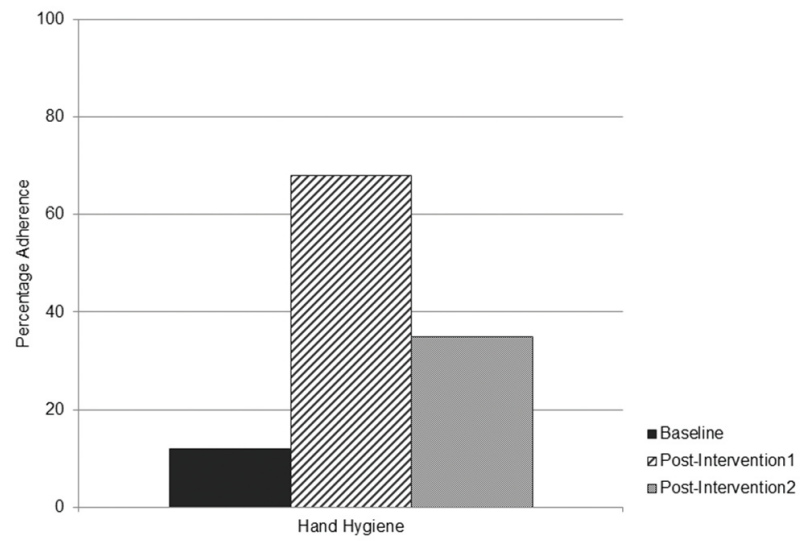

Figure 4: Adherence to hand hygeine before and after quality improvement intervention

It was apparent that a simple solution was not sufficient but that multiple aspects had to be addressed to impact on the problem. A team approach was crucial for the design and implementation of the intervention. The interdisciplinary team, consisting of the medical provider, nursing staff, administration, and respiratory therapy worked together to improve the care provided to residents dependent on ventilators. The various activities included education, increasing staff awareness, changes to the documentation, and a change in policy. A similar approach was undertaken in an acute rehabilitation center with 19 spinal cord injured patients dependent on mechanical ventilation. ${ }^{[15]}$ They highlighted the importance of a multi-disciplinary team approach to implementing this evidence-based protocol into practice.

An important aspect in creating change in this local nursing home facility was undertaking the organizational assessment to assess facilitators and barriers to change. The elements of context including culture, leadership, and evaluation have a major impact on the implementation and acceptance of evidence. ${ }^{[5,20]}$ The major challenge of this project was taking the VAP protocol, designed for the acute care setting, and tailoring it to a nursing home facility. The protocol was implemented within a context where the majority of the nursing staff is licensed vocational nurses. The implementation needed to consider their educational level and their scope of practice. Furthermore, there was limited focus on education and time and resources for quality improvement in this environment. This is consistent with findings by $\mathrm{Li}$, et al. ${ }^{[4]}$ who reported barriers to quality improvement included a lack of appropriate staff and resources to initiate and sustain the quality programs. Thus, gaining the participation of the organization's stakeholders was vital for overcoming this potential barrier. Facilitators reported in the literature include a dedicated project leader, awareness of the need for the practice change, and nurse ownership. ${ }^{[5,21]}$

Published by Sciedu Press
Through the organizational assessment and stakeholder interviews, we were able to gain the support for the practice change which also led to additional resources from nursing that were not initially anticipated. Estabrooks, et al. ${ }^{[22]}$ highlighted the importance of a positive context in promoting greater research utilization. This was found in the context of residential long-term care where they were testing their Alberta Context Tool. Of note, the indepth assessment phase garnered nursing support for the practice change and actually led to immediate changes in practice, including elevation of the head of the bed, one of the components of the VAP protocol. This did, however, mean that a true baseline on head of the bed elevation was never obtained.

Several measures that address the sustainability of this project included the ongoing process monitoring of the VAP protocol, the development of the VAP policy, and standardized physician admission order set consisting of the orders for the VAP protocol elements. Nurse champions were identified to assist with the implementation and process monitoring of the VAP protocol elements and hand hygiene process monitoring. The improvement in post-test scores suggests that the education on the care of residents with respiratory distress impacted the staff's knowledge on this theme, at least in the short term. To sustain nursing self-efficacy for providing respiratory care, it is important that ongoing education continues.

\section{Limitations}

A limitation of this project was lack of an interrupted time series design which entails repeated measures before and after the intervention. The changes we observed at 1 and 7 months, however, show sustained improvement in the two elements of the VAP protocol that are most closely related to VAP prevention, namely oral care and elevation of the head of the bed. While post-intervention data demonstrated a decrease in the percentage of readmissions related to respiratory distress, related to the design of the program, it is not possible to infer that this decrease is attributable to this program, given the pre-post design without concurrent controls.

\section{Conclusion}

The implementation of the VAP protocol related to ventilator care and respiratory care reflected a change in practice at this community nursing home. The implementation at the local facility serves as the prototypical implementation model for implementing QI at nursing home facilities. The essential elements included the detailed organizational assessment that garnered stakeholder participation and shaped the design and implementation of the QI intervention, and the multidisciplinary team participation. This quality improvement project responds to triple aim initiative of improving care, improving health, and reducing costs among residents within nursing home facilities. ${ }^{\text {[23] }}$ 


\section{References}

[1] Centers for Medicare and Medicaid Services. 2014. Available from: http://www.cms.gov/Medicare/Quality-Initiatives-P atient-Assessment-Instruments/NursingHomeQuality I nits/index.html

[2] United States Government Accountability Office. Nursing Homes: Private Investment Homes Sometimes Differed from other in Deficiencies, Staffing, and Finanical Performance. Washington, D.C.: Government Accountability Office; 2011.

[3] Horn SD, Sharkey SS, Hudak S, et al. Beyond CMS quality measure adjustments: identifying key resident and nursing home facility factors associated with quality measures. Journal of the American Medical Directors Association. 2010; 11(7): 500-505. PMid:20816338. http://dx.doi.org/10.1016/j.jamda.2009.10.008

[4] Li Y, Spector WD, Glance LG, et al. State "technical assistance programs" for nursing home quality improvement: variations and potential implications. Journal of Aging \& Social Policy. 2012; 24(4): 349-367. PMid:23216345. http://dx.doi.org/10.1080 /08959420.2012.735157

[5] McCormack B, Kitson A, Harvey G, et al. Getting evidence into practice: the meaning of context. Journal of Advanced Nursing. 2002; 38(1): 94-104. PMid:11895535. http://dx.doi.org/10. $1046 / j .1365-2648.2002 .02150 . x$

[6] Mor V, Intrator O, Feng Z, et al. The revolving door of rehospitalization from skilled nursing facilities. Health Affairs (Millwood). 2010; 29(1): 57-64. PMid:20048361. http://dx.doi.org/10.1377/h lthaff. 2009.0629

[7] Levinson DR. Medicare Nursing Home Resident Hospitalization Rates Merit Additional Monitoring. Department of Health and $\mathrm{Hu}-$ man Services, Office of Inspector General. 2013.

[8] Ouslander JG, Lamb G, Perloe M, et al. Potentially avoidable hospitalizations of nursing home residents: frequency, causes, and costs. Journal of the American Geriatrics Society. 2010; 58(4): 627635. PMid:20398146. http://dx. doi .org/10.1111/j.1532-5 $415.2010 .02768 . \mathrm{x}$

[9] Walsh EG, Freiman M, Haber S, et al. Cost Drivers for Dually Eligible Beneficiaries: Potentially Avoidable Hospitalizations from Nursing Facility, Skilled Nursing Facility, and Home and Community-Based Services Waiver Programs. 2010.

[10] O'Grady NP, Murray PR, Ames N. Preventing ventilator-associated pneumonia: does the evidence support the practice? JAMA. 2012; 307(23): 2534-2539. PMid:22797453.

[11] Zilberberg MD, Shorr AF, Kollef MH. Implementing quality improvements in the intensive care unit: ventilator bundle as an example. Critical Care Medicine. 2009; 37(1): 305-309. PMid:19050626. http://dx.doi.org/10.1097/CCM.0b013e3181926623

[12] Bird D, Zambuto A, O'Donnell C, et al. Adherence to ventilatorassociated pneumonia bundle and incidence of ventilator-associated pneumonia in the surgical intensive care unit. Archives of Surgery. 2010; 145(5): 465-470. PMid:20479345. http://dx.doi.org/1 0.1001 /archsurg. 2010.69

[13] Bonello RS, Fletcher CE, Becker WK, et al. An intensive care unit quality improvement collaborative in nine Department of Veterans Affairs hospitals: reducing ventilator-associated pneumonia and catheter-related bloodstream infection rates. The Joint Commission Journal on Quality and Patient Safety. 2008; 34(11): 639-645. PMid: 19025084.

[14] Sedwick MB, Lance-Smith M, Reeder SJ, et al. Using evidencebased practice to prevent ventilator-associated pneumonia. Critical Care Nursing. 2012; 32(4): 41-51. PMid:22855078. http://dx.d oi.org/10.4037/ccn2012964

[15] Crimlisk JT, Gustafson KA, Silva J. Translating guidelines into practice: ventilator-associated pneumonia prevention strategies in an acute rehabilitation unit. Dimesions of Critical Care Nursing. 2012; 31(2): 118-123. PMid:22333722. http://dx.doi.org/10.1097 /DCC. 0b013e3182446022

[16] Lamb G, Tappen R, Diaz S, et al. Avoidability of hospital transfers of nursing home residents: perspectives of frontline staff. Journal of the American Geriatrics Society. 2011; 59(9): 1665-1672. PMid:21883105. http://dx.doi.org/10.1111/j $.1532-5415.2011 .03556 . x$

[17] Goins TW Jr. Transitions to and from nursing facilities. North Carolina Medical Journal. 2012; 73(1): 51-54. PMid:22619856.

[18] How-to-Guide: Prevent Ventilator-Associated Pneumonia. The Institue for Healthcare Improvement. Cambridge: MA; 2012.

[19] Popejoy L, Galambos C, Vogelsmeier A. Hospital to Nursing Home Transition Challenges: Perceptions of Nursing Home Staff. Journal of Nursing Care Quality. 2014; 29(2): 103-109. PMid:24553358. http://dx.doi.org/10.1097/NCQ.0000000000000051

[20] Estabrooks CA, Squires JE, Cummings GG, et al. Development and assessment of the Alberta Context Tool. BMC Health Service Research. 2009; 9: 234. PMid:20003531. http://dx.doi .org/10. 1186/1472-6963-9-234

[21] Dogherty EJ, Harrison MB, Graham ID, et al. Turning knowledge into action at the point-of-care: the collective experience of nurses facilitating the implementation of evidence-based practice. Worldviews on Evidence-Based Nursing. 2013; 10(3): 129-139. PMid:23796066. http://dx.doi.org/10.1111/wvn.12009

[22] Estabrooks CA, Squires JE, Hayduk LA, et al. Advancing the argument for validity of the Alberta Context Tool with healthcare aides in residential long-term care. BMC Medical Research Methodology. 2011; 11: 107. PMid:21767378. http://dx.doi.org/10.1186 /1471-2288-11-107

[23] Ouslander JG, Maslow K. Geriatrics and the triple aim: defining preventable hospitalizations in the long-term care population. Journal of the American Geriatrics Society. 2012; 60(12): 2313-2318. PMid:23194066. http://dx.doi.org/10.1111/jgs. 12002 